\title{
Folliculotropic Mycosis Fungoides
}

National Cancer Institute

\section{Source}

National Cancer Institute. Folliculotropic Mycosis Fungoides. NCI Thesaurus. Code C35685.

A rare variant of mycosis fungoides, characterized by cerebriform lymphocytic infiltration of the hair follicles of the head and neck. Most cases show mucinous degeneration of the hair follicles, and are designated as mycosis fung oides-associated follicular mucinosis. Cases without mucinous degeneration have been reported as pilotropic mycosis fungoides. There is no difference in clinical presentation or outcome between mycosis fungoides-associated follicular mucinosis and pilotropic mycosis fungoides. In the recent WHO-EORTC classification, folliculotropic mycosis fungoides is the preferred term for all cases. 